\title{
Determining Fish Hunger State in a Smart Fish Farm Using Digital Signal Processing of the Water Current
}

\author{
Mbah, Frank Sunday ${ }^{1}$, Kabari, Ledisi Giok ${ }^{2}$ \\ ${ }^{1}$ Ignatius Ajuru University of Education, Port Harcourt, Nigeria \\ ${ }^{2}$ Ken Saro-Wiwa Polytechnic, Bori, Nigeria
}

\begin{abstract}
The traditional method of feeding the fish in an aquarium leads to wastage of the feed and poor water quality as the water easily gets contaminated and consequently hampers fish growth. Also, the method of having a pre-set time has not much effect to the problem as it may lead to unequal feed distribution and starvation of the smaller fishes. A behavioural pattern whereby the fish can be fed anytime will balance feed intake by the fish and promote growth. It will also reduce wastage. The identified state where the fish are more settled at the water surface with much movement thereby increasing the water current is used in this work. A gyroscope is proposed for the measurement of angular displacement caused by the water current. Because of the non-availability of the gyroscope and other necessary conditions, a dataset was formulated and histogram function in Microsoft Excel used in plotting the signal state of the two conditions. The difference in the two signal levels guarantees the reliability of this process in determining when it is more appropriate to feed the fish using an automated method in a smart fishpond.
\end{abstract}

Keywords: Fishpond, hunger state, gyroscope, water current, fish behaviour.

\section{INTRODUCTION}

$\mathrm{F}$ ish production using aquarium plays a very significant role in the provision of fish requirement of the entire world population. Key to this is the feeding process employed in the farm. Fish feeding is a very critical issue in aquaculture industry. It represents $40-50 \%$ of the total production cost[1]. Apart from cost, it accounts for the growth of the fishes. Underfeeding will result in the starvation of the fishes causing retardation in growth. Overfeeding on the other hand will cause wastage of feeds which affects water quality causing shortage of oxygen in the water[2][3] and excess ammonia[4]. The effect of this will be slow rate of fish growth rate and eventual reduction in productivity and profitability efficiency.

An efficient feeding process is therefore highly desired to counter the above negative effects. There are different methods that have been used in processing the feed sessions of the fish. The methods can be majorly classified as manual and automated methods. The manual feeding method is directly operated by a person using parameters such as the average body weight of the fishes [3]. It is based on scheduled meals and is responsible for several problems such as fish growth unproductivity, non-uniformity in growth, environmental impact on ocean floors in case of open ocean cages, and fish welfare as the competition on food is high due to the traditional feeding mechanism[1].

The automated Fish feeder is designed to feed the fishes in an aquarium at regular intervals [5] Hye et al. (2018). Different applications of this have proved to have better efficiency than the traditional or manual system. Most of the existing automatic feeding regime system were designed to operate at pre-set time [2] [5] [6][7]. Though better than the traditional system, the pre-set automatic feeders can as well result to underfeeding or overfeeding thus affecting negatively the development of the fish. There is therefore the need to identify and process the feed need of the fish based on its behavioural pattern that suggests its hunger state. When fishes need food, they will usually appear on the surface of the pond and tend to be more aggressive causing water ripples [4] or remarkable change in the water current. The specie of the fish must be taken into cognisance as different species have different feeding culture[8].

This research is intended to use the change in water current to visualise the difference in signals. This difference in signal can be used to determine when to feed the fish based on need. This will give a better Feed Conversion Ratio (FCR) resulting both in the growth of the fish and reduction in wastage of the feeds. Determining when the fish really needs food will reduce feed wastage, cause even growth, and reduce the ease at which the water is contaminated. In order to determine the signal state of a fishpond at the time the fish is hungry different from other normal state. We obtain Gyroscope Deflection at Normal state (Angles) and Gyroscope Deflection at Fish Hunger state (Angles) and plot it in Microsoft Excel to verify their signal states and relationship.

\section{RELATED WORKS}

Much research has been done and is still ongoing ho how to achieve better efficiency on fish feeding process. Much of the research achieved on automatic fish feed process is based on preset timing [5] while considering "A Novel Design and Implementation of Automated Feeding Mechanism in Fish Aquariums" used a microcontroller based fish feeder to implement pre-set time method. They designed a device that can enable both manual and automated operation using a microcontroller. The user can easily set the time with the keypad to dispense food in the aquarium. It is also possible to remotely control the food dispenser via a website. [6][7], also 
had a related design though with some differences in configuration.

[9], employed acoustic technologies using feedback controlled feeding system that uses sonic technology to measure feeding intensity.

A very related approach was done by [2] and [4]. Adegboye accomplished its design with the use of a novel 8-directional Chain Code generator algorithm developed for the extraction of signals from accelerometer for the escape and feeding activities. The approach used by [4] best satisfies the method in this work. They employed feeding behaviours by monitoring changes in water ripples caused by fish movement when the fishes are hungry. Gyroscope sensor was used to detect water ripples.

\section{METHODOLOGY}

This work is carried out based on the behavioural pattern of the fish settling more on the surface of the pond and being more aggressive at hunger state. Some other conditions of this scenario such as when the fishes are feeding must be taken into cognizance so as to eliminate false alert.

In carrying out this, a sensing device, such that can measure the change in water current velocity or a gyroscope that can measure angular displacement was used. The output of the gyroscope was measured in degrees. The more the water current, the higher the angular displacement of the gyroscope. The angular displacement varies with the disturbance on the water surface. When the fishes are hungry, aggressive and settled more on the surface of the pond, there will be higher displacement of the gyroscope than at normal time.

For the accuracy of this process, other conditions when the fishes are expected to be aggressive must be considered and rightly computed.

Depending on the size of the pond, a minimum of two sensors are to be deployed. This is to get an even response based on the water current. These two sensors must be compared for required value for further action to take place. The operational flow chart is as shown in figure 5 .

Behaviour of fishes differ based on the specie. Two gyroscopes are assumed in this case. Their signal states must be checked and compared. If they are up to a required state that suggests hunger state of the fishes, a delay of 60 seconds is evolved to ensure it's not just a transient movement. If the optimum state lasts for up to 60 seconds on the two sensors, then the feeder will be activated to feed the fishes else sensor monitoring continues. At each moment the fishes are fed, a delay of 60 minutes is allowed before commencement of further monitoring of the sensors. Table 1 shows the normal fishpond water current condition and the condition of the water current at the hunger state of the fish. The signal conditions are plotted using the Microsoft Excel histogram function. Figure 1 is the flow chart that describes the operation on how the fish can be fed based on its behavioural pattern. Two gyroscopes are assumed in this case.

Location of Fish Farm: Department of Fisheries, Rivers State University, Port Harcourt, Nigeria. Fish pond Specification: Plastic Tank with Length $=100 \mathrm{~cm}$, Width $=80 \mathrm{~cm}$, Height $=$ $100 \mathrm{~cm}$, Water level in the tank $=66 \mathrm{~cm}$. Figure 1 shows the plastic tank for the fish pond with the given specifications as stated. Gyroscope is a locally fabricated gyroscope using Arduino Uno, Potentiometer, Steel rod, and Floater. Figure 2 shows the Gyroscope as specified. Figure 3 shows gyroscope installed on the fish pond. Water current being monitored using Laptop that is connected to the gyroscope. Figure 4 shows screenshot taken from the changes in water current. Signal shows transition from less turbulent water current to more turbulent one.

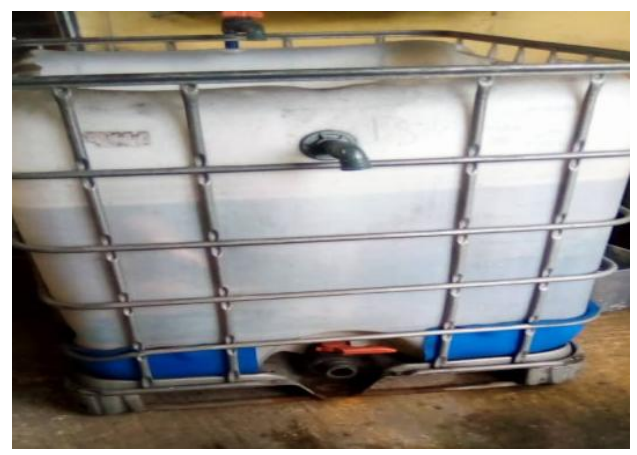

Figure 1: Plastic Tank for the fish pond

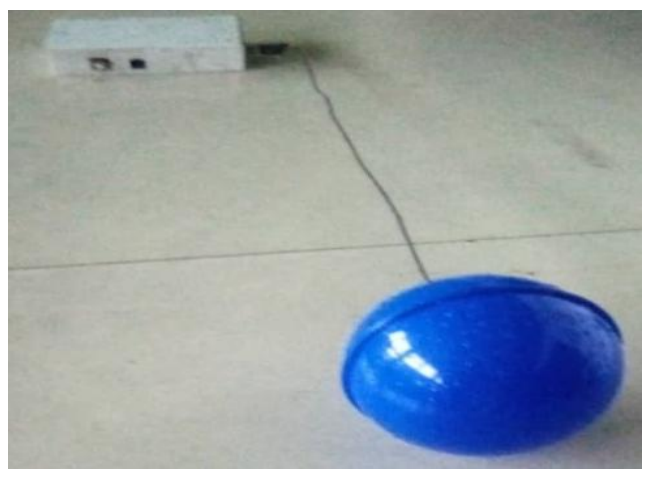

Figure 2: Gyroscope

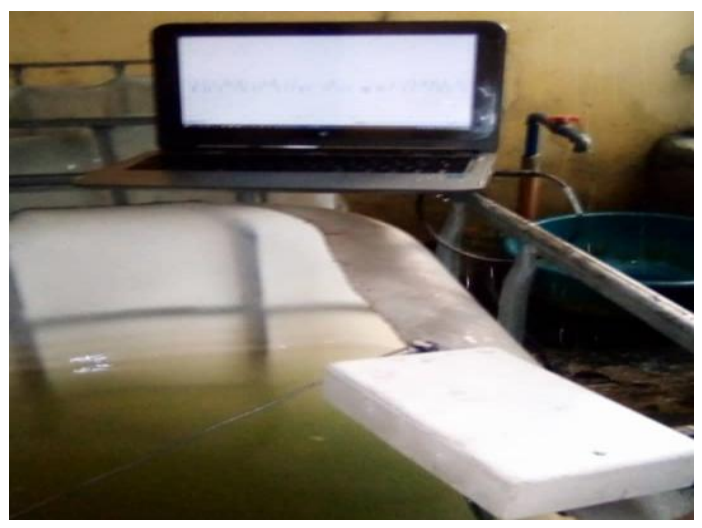

Figure 3: Showing gyroscope installed on the fish pond 


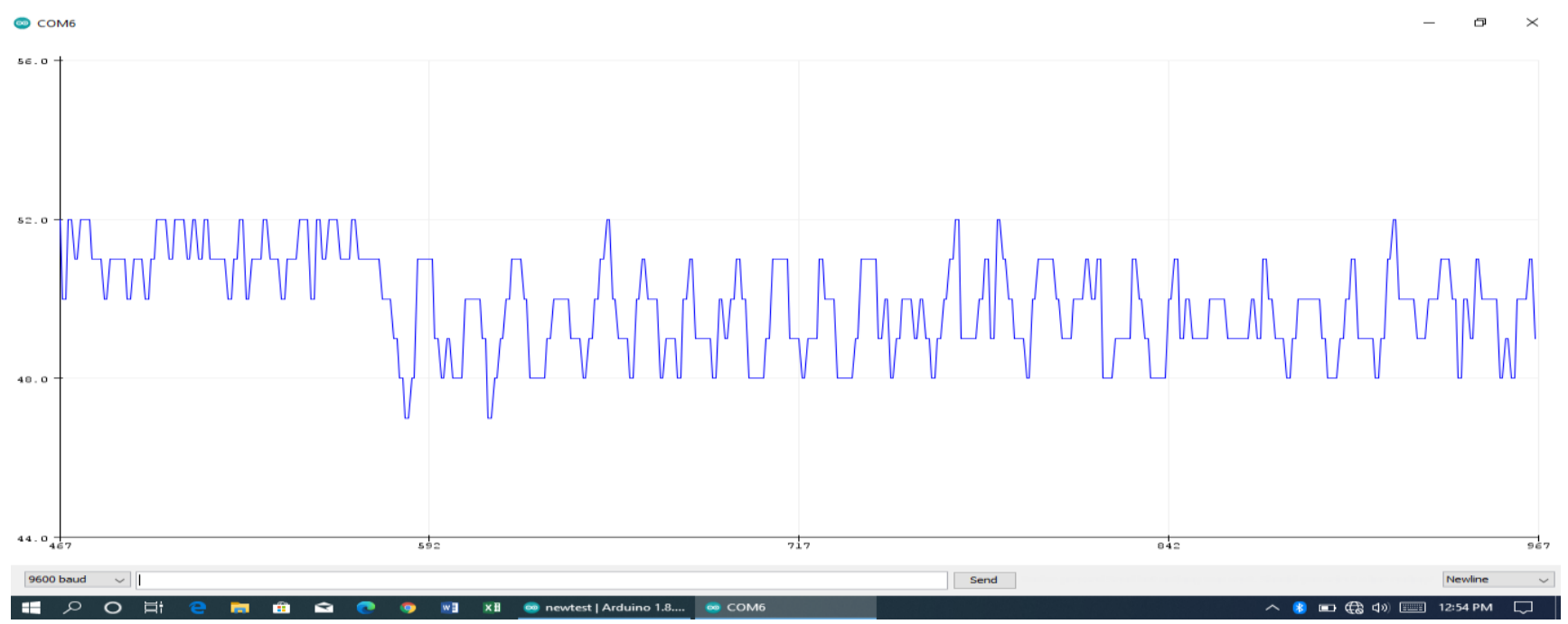

Figure 4: Showing screenshot taken from the changes in water current

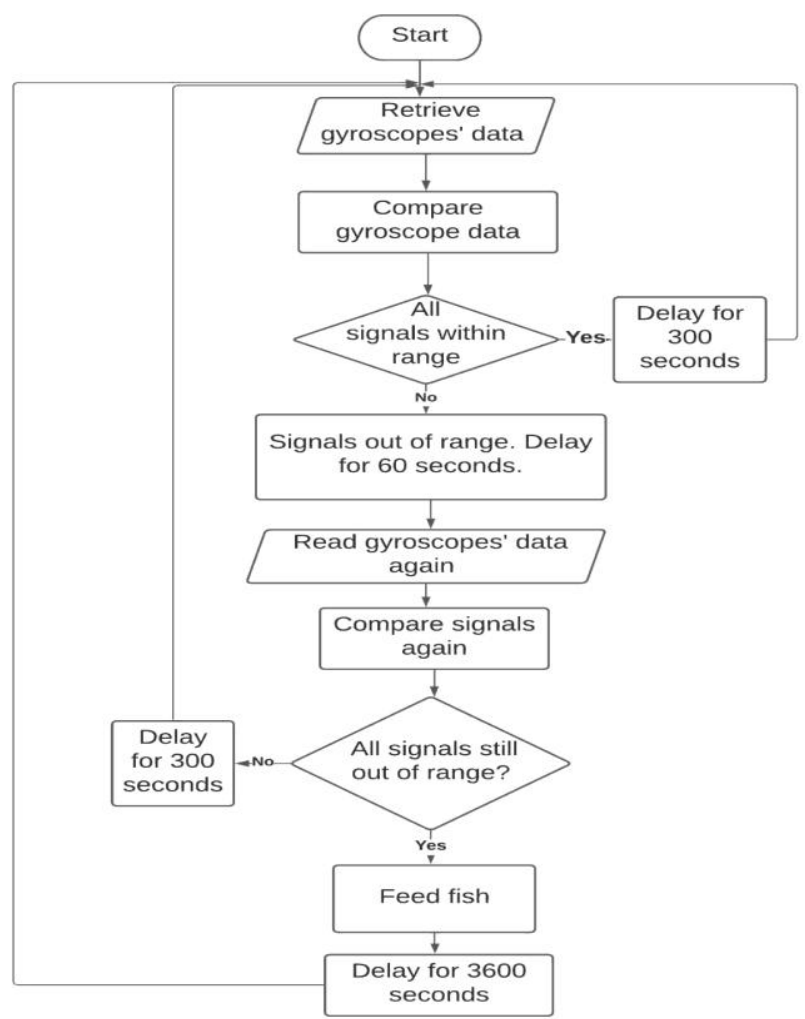

Figure 5: Flow chart to determine when to feed the fish. (Drawn with lucid chart)

Their signal states must be checked and compared. If they are within the level that suggests hunger state of the fishes, a delay of 60 seconds is evolved to ensure it is not just a transient movement. If this state lasts for up to 60 seconds on the two sensors, then the feeder will be activated to feed the fishes else sensor monitoring is delayed for five minutes for monitoring to continue. At each moment the fishes are fed, a delay of 60 minutes (3600 seconds) is allowed before commencement of further monitoring of the sensors.

\section{RESULTS AND DISCUSSION}

The water current displacement in degrees at normal water current state and at fish hunger state are expressed on the following signals based on the dataset. Figure 6 illustrates the pond water current at normal state when the fish does not create turbulence on the water surface. At this state, movement of fish is not aggressive. The displacement of water ripples or current is low. Figure 7 illustrates the water current at fish hunger state. Due to turbulence created by the fish at hunger state, the displacement is higher when compared to the normal state in figure 6 .

Table 1. Water current at the normal and hunger state of the fish for a time frame of 60 seconds.

\begin{tabular}{|c|c|c|}
\hline $\begin{array}{c}\text { Time } \\
\text { (Seconds) }\end{array}$ & $\begin{array}{c}\text { Gyroscope Deflection at } \\
\text { Normal state (Angles) }\end{array}$ & $\begin{array}{c}\text { Gyroscope Deflection at } \\
\text { Fish Hunger state (Angles) }\end{array}$ \\
\hline 1 & 2 & 10 \\
\hline 2 & 3 & 11 \\
\hline 3 & 3 & 12 \\
\hline 4 & 2 & 12 \\
\hline 5 & 4 & 11 \\
\hline 6 & 4 & 11 \\
\hline 7 & 4 & 11 \\
\hline 8 & 5 & 11 \\
\hline 9 & 4 & 11 \\
\hline 10 & 5 & 12 \\
\hline 11 & 5 & 12 \\
\hline 12 & 5 & 12 \\
\hline 13 & 3 & 10 \\
\hline 14 & 3 & 10 \\
\hline
\end{tabular}


International Journal of Research and Innovation in Applied Science (IJRIAS) | Volume VI, Issue VIII, August 2021|ISSN 2454-6194

\begin{tabular}{|c|c|c|}
\hline 15 & 4 & 11 \\
\hline 16 & 3 & 10 \\
\hline 17 & 3 & 11 \\
\hline 18 & 3 & 11 \\
\hline 19 & 3 & 10 \\
\hline 20 & 4 & 11 \\
\hline 21 & 3 & 12 \\
\hline 22 & 5 & 12 \\
\hline 23 & 5 & 10 \\
\hline 24 & 5 & 9 \\
\hline 25 & 5 & 9 \\
\hline 26 & 4 & 9 \\
\hline 27 & 3 & 8 \\
\hline 28 & 2 & 8 \\
\hline 29 & 2 & 8 \\
\hline 30 & 2 & 8 \\
\hline 31 & 1 & 9 \\
\hline 32 & 1 & 9 \\
\hline 33 & 1 & 9 \\
\hline 34 & 2 & 9 \\
\hline 35 & 2 & 9 \\
\hline 36 & 2 & 10 \\
\hline 37 & 1 & 10 \\
\hline
\end{tabular}

\begin{tabular}{|c|c|c|}
\hline 38 & 1 & 10 \\
\hline 39 & 2 & 10 \\
\hline 40 & 2 & 11 \\
\hline 41 & 2 & 11 \\
\hline 42 & 2 & 11 \\
\hline 43 & 2 & 12 \\
\hline 44 & 2 & 12 \\
\hline 45 & 2 & 11 \\
\hline 46 & 3 & 12 \\
\hline 47 & 3 & 11 \\
\hline 48 & 2 & 12 \\
\hline 49 & 2 & 11 \\
\hline 50 & 3 & 12 \\
\hline 51 & 3 & 11 \\
\hline 52 & 3 & 10 \\
\hline 53 & 3 & 10 \\
\hline 54 & 4 & 10 \\
\hline 55 & 2 & 10 \\
\hline 56 & 3 & 9 \\
\hline 57 & 3 & 9 \\
\hline 58 & 4 & 9 \\
\hline 59 & 4 & 8 \\
\hline 60 & 4 & 9 \\
\hline
\end{tabular}

\section{Ideal Water_Current (deg.)}

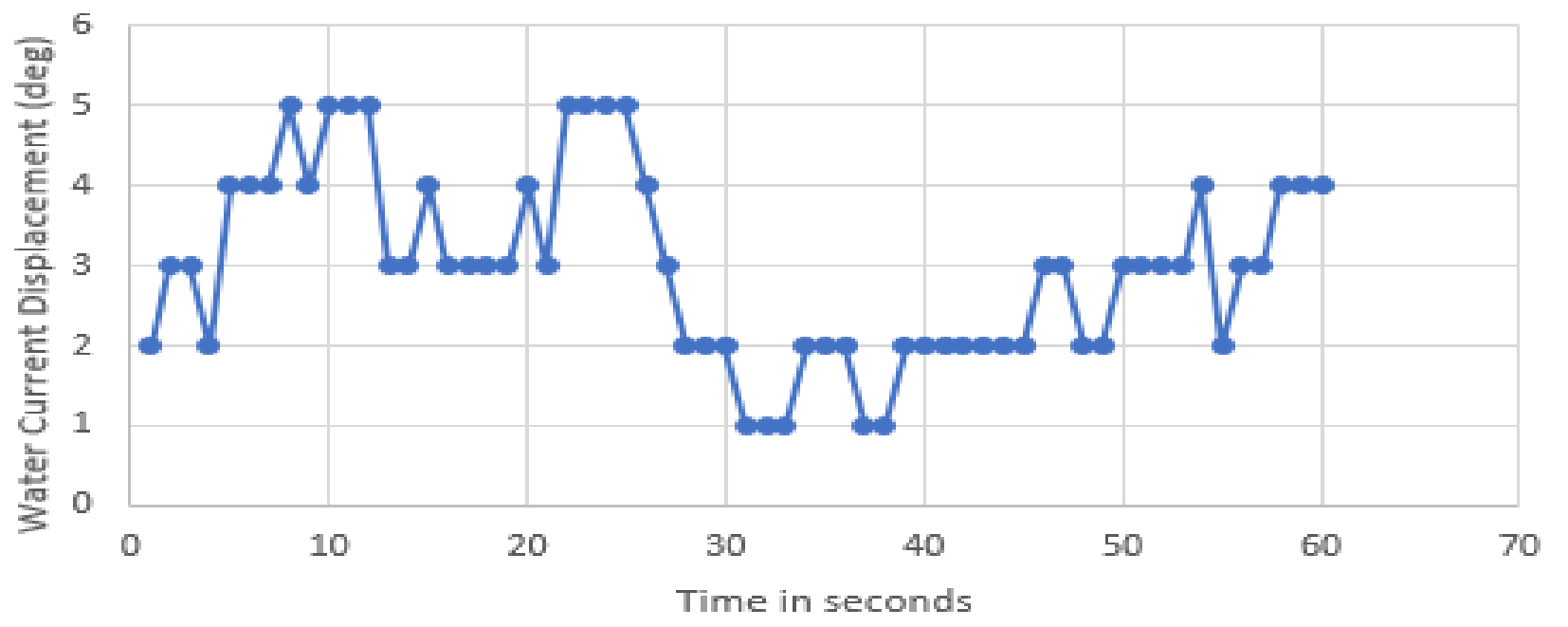

Figure 6: Water current at fish normal state. 


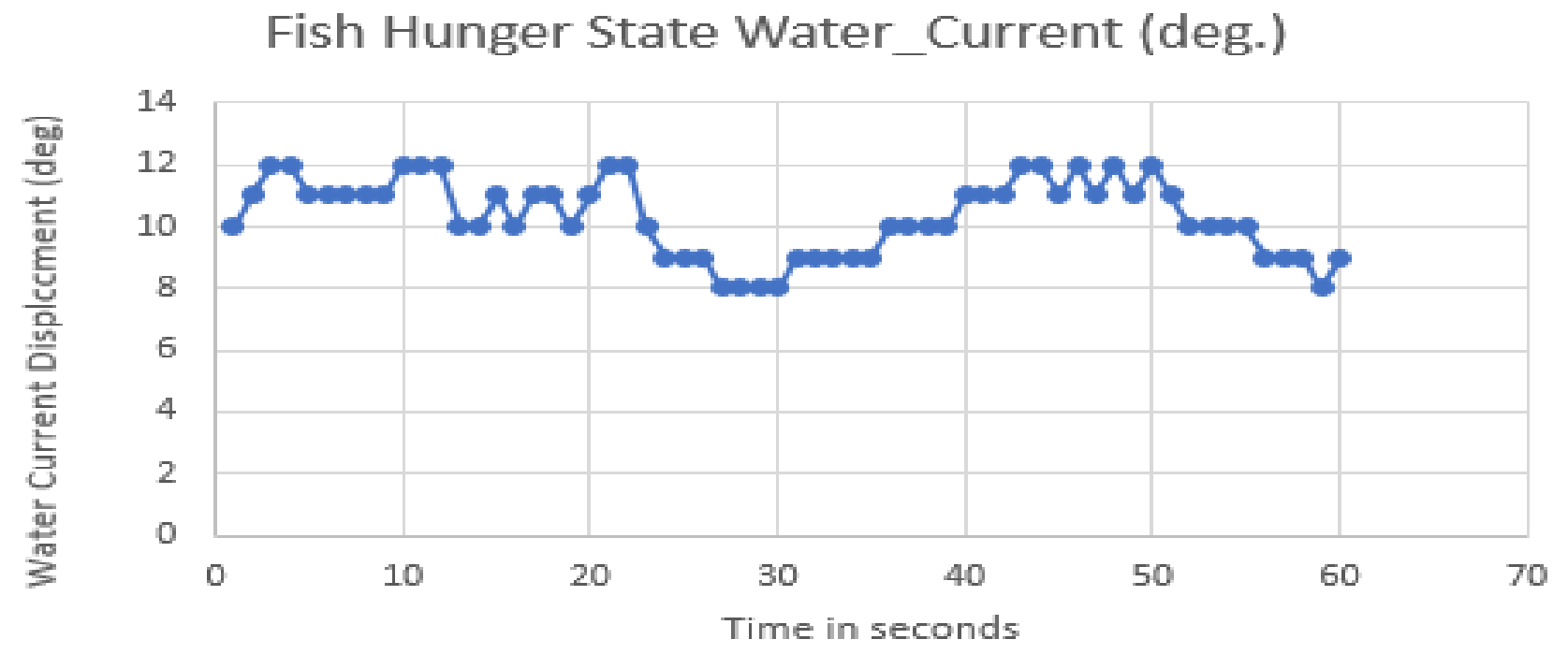

Figure 7: Signal of water current at fish hunger state.

\section{Comparative Signal for Normal and Fish Hunger State Water Current}

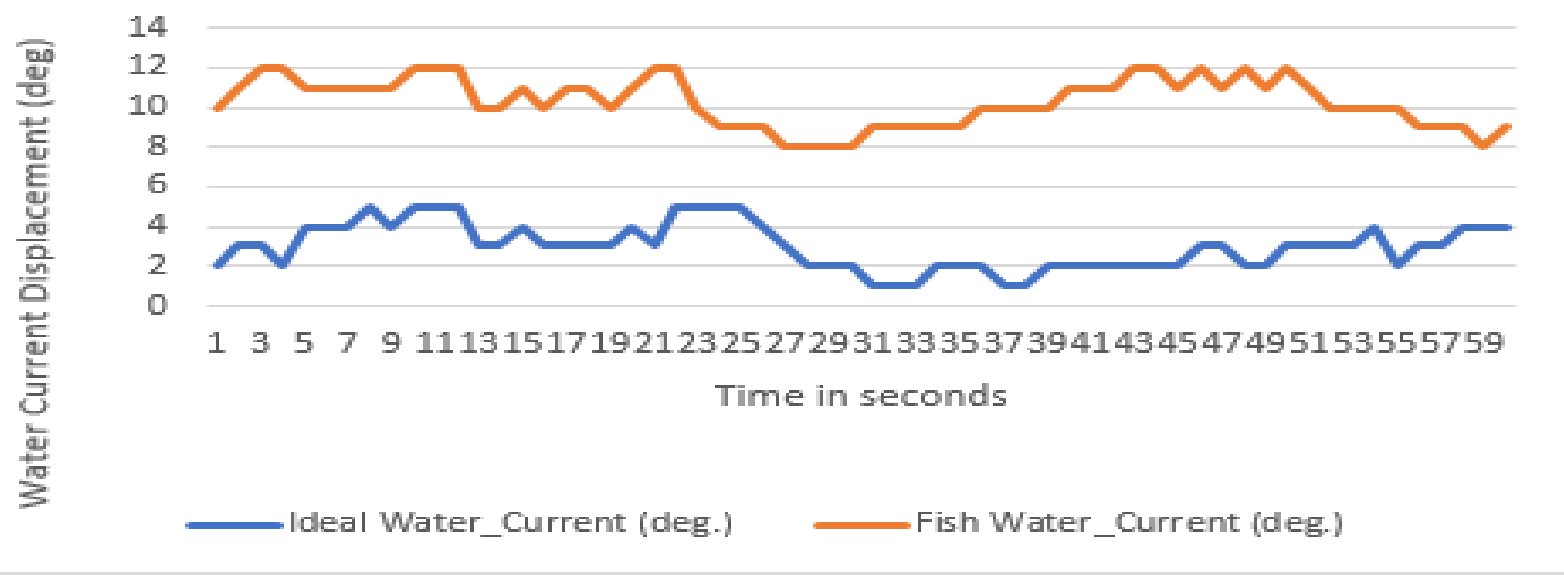

Figure 8: Comparative signal of water current at fish normal and hunger state.

Figure 8 shows the difference in water current displacement (i.e. angular displacement) when the fish moves normally and when it moves aggressively due to its hunger state. From the signal, it is observed that the displacement of the gyroscope (or surface pond water turbulence) is higher when the fishes are hungry, aggressive and more on the surface of the pond than at other non-aggressive time. At such a time, coupled with other necessary computations for a smart fishpond, the fish can be fed without human intervention and at the time it really needs the food.

\section{CONCLUSION}

From the analysis carried out on the water current signal at the normal state of the pond and the hunger state when the fish are more settled at the surface of the water waiting for food, it is very evident in the difference of the signal levels. This difference can be used to activate the feeder in a smart pond. Feed wastage will be minimised leading to better water quality control.

\section{REFERENCES}

[1] AlZubi, H. S. , Al-Nuaimy, W.,J. Buckley \& Young, I. "An intelligent behavior-based fish feeding system," 2016 13th International Multi-Conference on Systems, Signals \& Devices (SSD), Leipzig, Germany, 2016, pp. 22-29, doi: 10.1109/SSD.2016.7473754.

[2] Adegboye, M., Aibinu, A., Kolo, J., Folorunso, T., Aliyu, I., \& Ho, Lee. (2019). Intelligent Fish Feeding Regime System using Vibration Analysis. $\quad 3.8$. https://www.researchgate.net/publication/343179730_Intelligent_ Fish_Feeding_Regime_System_using_Vibration_Analysis.

[3] Adegboye, M., Aibinu, A. Kolo, J., Aliyu, I., Folorunso, T., \& Lee, S. (2020). Incorporating Intelligence in Fish Feeding System for Dispensing Feed Based on Fish Feeding Intensity. IEEE Access. PP. 1-1. 10.1109/ACCESS.2020.2994442. 
[4] Aisuwarya, R., \& Suhendra, E. (2018). Development of Automatic Fish Feeding System based on Gasping Behavior. 470-473. 10.1109/ICITSI.2018.8696050. 2018 International Conference on Information Technology Systems and Innovation (ICITSI). DOI: 10.1109/ICITSI.2018.8696050.

[5] Hye, M. A., Akter, M. M. Jahangir, A. M. \& Zaman H. U., "A Novel Design and Implementation of Automated Feeding Mechanism in Fish Aquariums," 2018 2nd International Conference on Electronics, Materials Engineering \& NanoTechnology (IEMENTech), Kolkata, India, 2018, pp. 1-7, doi: 10.1109/IEMENTECH.2018.8465332.

[6] Uzama, F., (2018). Automatic Controlling of Fish Feeding System. International Journal for Research in Applied Science. DOI: 10.22214/ijraset.2018.7050.
[7] Noor,. M. Z. H Hussian, A. K., Saaid, M. F. Ali, M. S. A. M., \& Zolkapli, M. "The design and development of automatic fish feeder system using PIC microcontroller," 2012 IEEE Control and System Graduate Research Colloquium, Shah Alam, Malaysia, 2012, pp. 343-347, doi: 10.1109/ICSGRC.2012.6287189.

[8] Alammar, M., \& Al-Ataby, A. (2018). An intelligent approach of the Fish feeding system. 85-97. 10.5121/csit.2018.81506. 3rd International Conference on Data Mining \& Knowledge Management. DOI: 10.5121/csit.2018.81506.

[9] Melanie R., Romi, N., Anneleen, S., Carter, U., \& Donald, D. (2018). Automated feeding systems in pond production of Pacific white shrimp.

https://www.researchgate.net/publication/330566608_Automated_ feeding_systems_in_pond_production_of_Pacific_white_shrimp. 